\title{
Central Projections of the Lateral Line and Eighth Nerves in the Bowfin, Amia calva
}

\author{
CATHERINE A. MCCORMICK \\ Division of Biological Sciences, The University of Michigan, Ann Arbor, \\ Michigan 48109
}

\begin{abstract}
The first-order connections of the anterior and posterior lateral line nerves and of the eighth nerve were determined in the bowfin, Amia calva, using experimental degeneration and anterograde HRP transport techniques. The termination sites of these nerves define a dorsal lateralis cell column and a ventral octavus cell column.

The anterior and posterior lateralis nerves distribute ipsilaterally to two medullary nuclei-nucleus medialis and nucleus caudalis. Nucleus medialis comprises the rostral two-thirds of the lateralis column and contains large, Purkinje-like cells dorsally and polygonal, granule, and fusiform cells ventrally. Nucleus caudalis is located posterior to nucleus medialis and consists of small, granule cells. Anterior lateral is fibers terminate ventrally to ventromedially in both nucleus medialis and nucleus caudalis. Posterior lateralis fibers terminate dorsally to dorsolaterally within these two nuclei. A sparse anterior lateralis input may also be present on the dendrites of one of the nuclei within the octavus cell column, nucleus magnocellularis. In contrast, the anterior and posterior rami of the eighth nerve each terminate within four medullary nuclei which comprise the octavus cell column: the anterior, magnocellular, descending, and posterior octavus nuclei. An eighth nerve projection to the medial reticular formation is also present.

Some fibers of the lateralis and eighth nerves terminate within the ipsilateral eminentia granularis of the cerebellum. Lateralis fibers distribute to approximately the lateral half of this structure with posterior lateral line fibers terminating laterally and anterior lateral line fibers terminating medially. Eighth nerve fibers distribute to the medial half of the eminentia granularis.
\end{abstract}

Early anatomical studies frequently described the lateral line and eighth nerves of fish as providing extensive input to common first-order nuclei-an observation which influenced hypotheses concerning the evolution of vertebrate audition and its central representation. In contrast, most recent investigations of these inputs have demonstrated little convergence of the primary terminations of the eighth and lateral line nerves in a variety of fishes (Boord and Campbell, '77; Maler et al., '73a,b; Koester and Boord, '78; Northcutt, '79a,b, '80; Boord and Roberts, '80) and an aquatic amphibian (Boord and Eiswerth, '72; Campbell and Boord, '74). The present study provides a detailed description of the lateral line (lateralis) and eighth (octavus) nerves in the bowfin, Amia calva, and thereby experimentally identifies for the first time the constituents and boundaries of the entire octavolateralis area in a single species of bony fish.

The octavolateralis area, the medullary region containing the first-order lateralis and octavus nuclei, is usually referred to as the acousticolateralis area. However, since this area includes the termination sites of vestibular as well as acoustic and lateralis fibers, the more inclusive term "octavolateralis" will be employed here.

In Amia, the anterior and posterior lateralis nerves innervate mechanoreceptive sensory

\footnotetext{
Catherine McCormick's present address is Department of Anatomy, Georgetown University Schools of Medicine and Dentistry, 3900 Reservoir Rd., N.W., Washington D.C. 20007
} 
cells distributed on the anterior and posterior portions of the animal, respectively. On the basis of studies in other species, the mechanoreceptors of the lateralis system appear to be stimulated by low-frequency water displacements (Harris and van Bergeijk, '62; Bauknight et al., '76; Kroese et al., '78; Strelioff and Honrubia, '78). Each of the lateralis nerves in Amia possesses its own ganglion and enters the brain as a single root separate from other cranial nerves (Fig. 1). The octavus nerve consists of an anterior and a posterior ramus (Fig. 1), each with its own ganglion, and innervates the sensory maculae of the labyrinth. In Amia, the anterior ramus supplies the utriculus, the anterior and horizontal semicircular canals, and a portion of the sacculus-a presumed auditory end organ. The posterior ramus also innervates the sacculus, as well as the lagena, macula neglecta, and the posterior semicircular canal (Retzius, 1881; McCormick, 78). Each of the octavus rami in Amia thus carries both auditory and vestibular fibers.

\section{METHODS}

Serial, cresyl violet-stained, transverse sections were prepared from a nonexperimental brain for study of the cytoarchitecture of the octavolateralis area. This series was also used to construct Figure 2, in which each of the

Abbrewations (for Figs. 2-7)

Ant (Ant VHI) anterior octavus nucleus

Caud nucleus caudalis

CB corpus of the cerebellum

CC cerebellar crest

Desc (Desc VIII) descending actavus nucleus

EG eminentia granularis

Med nucleus medialis

Mg nucleus magnocellularis

MLF medial longitudinal fasiculus

MRF medial reticular formation

N ALL anterior lateral line nerve

N PLL posterior lateral line nerve

$\mathrm{N}$ VIII eighth nerve

$\mathrm{N}$ VIII anterior ramus of the eighth nerve

$\mathrm{N}$ VUp posterior ramus of the eighth nerve

N IX glossopharyngeal nerve

$\mathrm{N} X$ vagus nerve

Post (Post VIII) posteriur octavus nucleus

$\mathrm{V}$ trigeminal motor nucleus

$\mathrm{VL}$ vagal lobe

V-VII trigeminal and facial nerves

VII facial motor nucleus

$\mathrm{X}$ motor nucleus of the vagus nerve octavolateralis nuclei was projected onto the lateral surface of the medulla.

The first-order projections of the lateralis and eighth nerves were determined using experimental degeneration and anterograde HRP transport techniques. Mature specimens of A mia calva were anesthetized by immersion in a $0.025 \%$ solution of tricaine methanesulfonate (MS-222). One of the lateralis nerves or one of the rami of the octavus nerve was exposed using a dorsal approach.

In the experimental degeneration cases, a given nerve was transected proximal to its ganglion. The location of the ganglion associated with each of the nerves had been previously determined (McCormick, 1978) in a perfused specimen using the Sudan Black B Method (Rasmussen, '61). Following transection, Gelfoam (absorbable gelatin sponge; Upjohn Co.) was inserted into the cranial opening to protect the brain from the dental acrylic used to seal up the opening in the cranium. Three cases, having survival times of 6 to 18 days, were obtained for each nerve. Additionally, the glossopharyngeal nerve was transected in one animal in order to determine whether it contains a lateralis component, as described by Allis (1889), Kingsbury
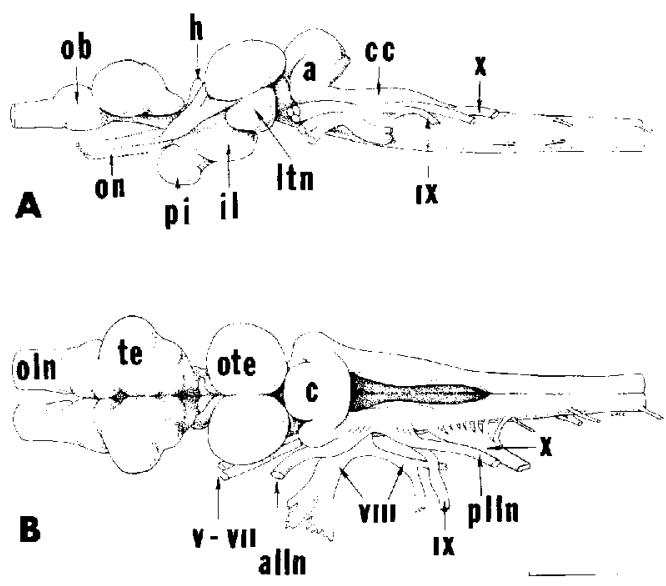

Fig. 1. A. Lateral view of the brain of A mia ealva. B. Dorsal view of the brain of Amia calva. Bar scale $=1 \mathrm{~mm}$. floaned by Dr. R.G. Northeutt) Abbreviations: a, eminentia granularis; alln, anterior lateral line nerve; $c$, cerebellum, cc, cerebellar crest; h, habenula; il, inferior lobe; ltn, torus lateralis; ob, olfactory bulb; oln, olfactory nerve; on, optic nerve; ote, optic tectum; pi, pituitary; plln, posterior lateral line nerve; te, telencephalon; V-VII, trigeminal and facial nerves; VIII, eighth nerve; $I X$, glossopharyngeal nerve; $X$, vagus nerve. 


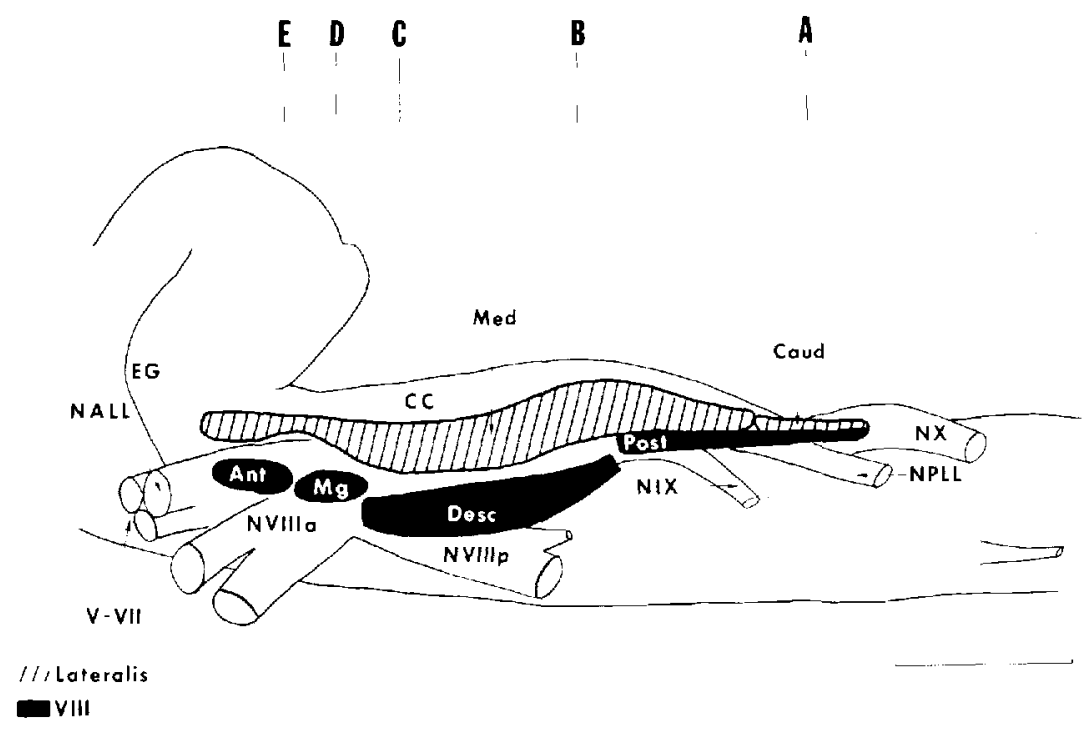

Fig. 2. Lateral view of the brainstem of Amia calva showing the positions of all six octavolateralis nuclei. Each nucleus has been projected onto the lateral surface of the brain. Bar scale $=1 \mathrm{~mm}$.

(1897), and Norris (25). All animals were perfused with $0.7 \%$ saline followed by $10 \%$ formalin. The brains were fixed in $10 \%$ formalin for an additional week and then embedded in $25 \%$ gelatin. Transverse, frozen sections were cut at $30-33 \mu \mathrm{m}$ and processed according to the Wiitanen modification of Fink-Heimer procedure II (Wiitanen, '69). Sections adjacent to those processed for degenerating axons and terminals were stained with cresyl violet to permit accurate identification of termination sites.

The connections of the lateralis and octavus nerves were also visualized using anterograde transport of HRP. At least two cases were obtained for each of the nerves, and in one animal the connections of the glossopharyngeal nerve were determined using this method. In each instance, a given nerve was transected at or distal to its ganglion. Between 1 and 2 microliters of $35 \%$ HRP (Sigma Type VI) in distilled water was injected into the proximal nerve stump using a 5-microliter Hamilton syringe. A small HRP-soaked Gelfoam plug was then applied to the end of the proximal stump, and this portion of the nerve was then coated with petroleum jelly to prevent seepage of HRP to other structures. Gelfoam and dental acrylic were used to close the skull as in the experimental degeneration cases. Survival times ranged from 5 to 14 days, and the tissue was processed according to the method of Mesulam (78). Prior to sectioning, the brains were embedded in a cool gelatin medium $(10 \mathrm{gm}$ gelatin, $10 \mathrm{gm}$ sucrose, $100 \mathrm{ml}$ distilled water). The blocks were fixed for 4 to 8 hours in some of the perfusate fixative (Mesulam, '78) which had $10 \%$ sucrose added to it to prevent freezing artifact. The brains were sectioned immediately after block fixation or transferred to Mesulam's final rinse perfusate for later sectioning. 'Transverse, frozen sections cut at 40 or $60 \mu \mathrm{m}$ were reacted with tetramethyl benzidine and counterstained with neutral red (Mesulam, '78).

\section{RESULTS}

\section{Cytoarchitecture of the octavolateralis area}

The octavolateralis area of Amia contains six nuclei which are organized into two longitudinal columns-a dorsal lateralis column and a ventral octavus column (Fig. 2). These cell columns occupy an area which extends 
rostrocaudally from the level of the trigeminal motor root to the level of the anterior rootlets of the vagus nerve.

The lateralis cell column is composed of two nuclei-nucleus medialis rostrally and nucleus caudalis caudally. Nucleus medialis, which forms the major portion of the lateralis column (Fig. 3), consists of a dorsal region of large, Purkinje-like cells and a ventral region containing polygonal, fusiform, and granule cells. The Purkinje-like cells are bipolar and generally have a vertical orientation. The ventral dendrites of the vertically oriented cells ramify in the ventral region of nucleus medialis, whereas the dorsal dendrites extend into an overlying molecular layer, the cerebellar crest. The cerebellar crest, which is a caudal continuation of the molecular layer of the cerebellum, is closely associated with nucleus medialis and caps it throughout its entire extent. Nucleus medialis has its rostral limit at the level at which the cerebellar crest becomes continuous with the molecular layer of the cerebellum. At this level, the Purkinje-like cells appear to be continuous with the Purkinje cell layer of the cerebellum. The caudal limits of the cerebellar crest and nucleus medialis are nearly coincident (Fig. 2).

The posterior one-quarter of the dorsal lateralis cell column is formed by nucleus caudal is (Figs. 2A, 3A). This cell group occupies the dorsolateral region of the medulla and consists of small granule cells with diameters of approximately $5 \mu \mathrm{m}$. It is bounded ventrally by a portion of the octavus cell column, the posterior octavus nucleus, and medially by the funicular nuclei.

The ventral, octavus cell column is composed of four nuclei. In a rostrocaudal direction these are: the anterior octavus nucleus, nucleus magnocellularis, the descending octavus nucleus, and the posterior octavus nucleus (Figs. 2,3 ).

The anterior octavus nucleus is, in A mia, an indistinct group of small and medium-sized bipolar cells lying ventral to nucleus medialis (Fig. 3E). Its rostral boundary is coincident with that of nucleus medialis, and it is replaced caudally by nucleus magnocellularis.

Nucleus magnocellularis is a prominant cell group with consists of large $(90 \times 40 \mu \mathrm{m})$, multipolar neurons which stain darkly with cresyl violet. Its rostrocaudal extent is coincident with the entrance of the two octavus rami, and it is located medially, just dorsal to the sulcus limitans (Fig. 3D).

The descending octavus nucleus, located caudal to nucleus magnocellularis, forms the largest component of the octavus column in
Amia (Fig. 3B,C). This nucleus consists of medium-sized bipolar and polygonal cells which are less darkly staining than those found in the ventral portion of nucleus medialis. The descending octavus nucleus is roughly $\mathrm{C}$ shaped, with the majority of cells located in the dorsal arm. A few of the more ventral cells are very large $(60 \mu \mathrm{m}$ along their long axis) and stain more darkly than the other elements of this nucleus. The most ventral cells are scattered among horizontally coursing fibers, some of which arise from the eighth nerve. The caudal boundary of the descending octavus nucleus is found at a level just rostral to the entrance of the glossopharyngeal nerve.

The posterior octavus nucleus, the most caudal cell group of the octavus column, lies at the lateral surface of the medulla ventral to the nucleus caudalis of the lateralis cell column (Fig. 3A). It consists of a small population of granule cells (diameters approximately $5 \mu \mathrm{m}$ ) which are more scattered than the cells of the overlying nucleus caudalis.

\section{Projections of the anterior and posterior lateral line nerves}

The anterior lateral line nerve enters the medulla as a single root near the entrance of the anterior octavus ramus (Fig. 4D). At this level, the anterior lateralis fibers course toward the medial wall of the medulla, ventral to the cerebellar crest. Some of the fibers come in contact with the distal dendrites of the most dorsally situated cells of nucleus magnocellularis, and may terminate sparsely on some of these processes. The majority of the fibers, however, form ascending and descending bundles lateral to the vagal lobes.

The fibers of the posterior lateral line nerve also form a single root and enter the medulla immediately anterior to the entrance of the glossopharyngeal nerve and posterior to the posterior octavus ramus (Fig. 5B). The fibers course dorsally and form ascending and descending bundles on the lateral aspect of the medulla ventral to the cerebellar crest.

Nucleus medialis receives an ipsilateral lateralis input throughout its entire extent. Anterior lateral line fibers terminate in its medial and ventromedial regions (Figs. $4 \mathrm{~B}-\mathrm{E}, 8 \mathrm{~B}, \mathrm{E}$ ), whereas posterior lateral line fibers terminate primarily in its dorsolateral and dorsal regions (Figs. 5B-E, 8A,D). Both lateral line nerves appear to provide input to all three cell types in the ventral part of nucleus medialis. Lateralis fibers of both nerves also terminate sparsely on the ventral dendrites of the Purkinje-like cells. 


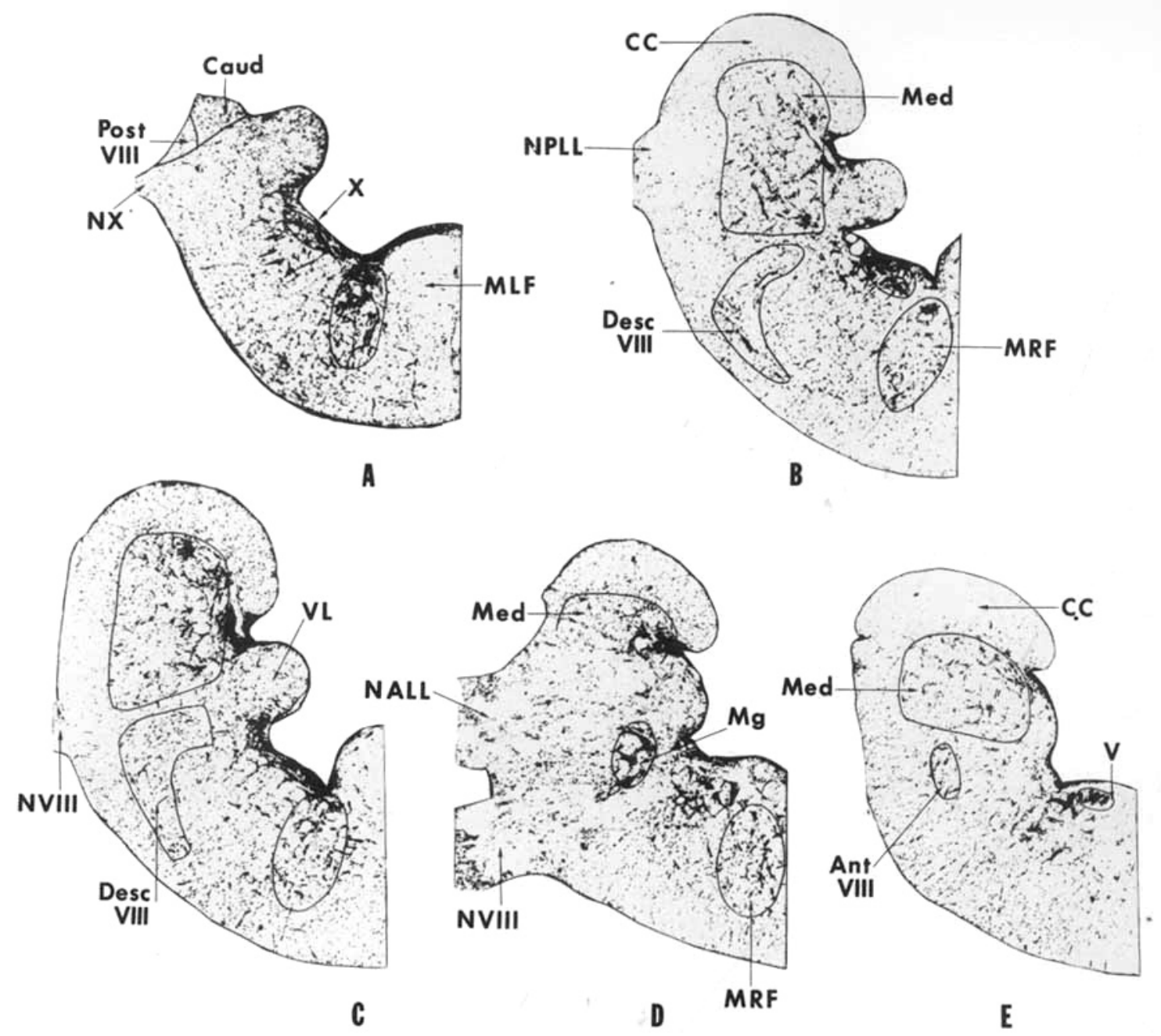

Fig. 3. A E. Photomicrographs of transverse sections through the octavolateralis area at the levels indicated in Figure 2. Cresyl violet. Bar scale $=1 \mathrm{~mm}$.

The descending bundles of both lateralis nerves also terminate ipsilaterally in nucleus caudalis. Anterior lateralis fibers supply approximately the medial half of the nucleus (Figs. 4A, 9B), whereas posterior lateralis fibers distribute to the lateral half (Figs. 5A, 9A).

Some fibers of the ascending bundle of each lateralis nerve terminate in the ipsilateral cerebellum. First-order lateral line input to the cerebellum is restricted to the lateral half of the eminentia granularis. In Amia, the eminentia granularis contains a layer of Purkinje cells in addition to the granule cells. It lies deep to the molecular layer except rostrally, where the granule cells lie on the cerebellar surface (van der Horst, '25; Larsell, '67; Nieuwenhuys, '67). The posterior lateral line fibers course along the edge of the Purkinje cell layer and, as they ascend, terminate on the most laterally situated granule cells. Whether the Purkinje cells receive an input is uncertain. The densest termination site is on the rostral granule cells which lie on the cerebellar surface (Fig. 7A), although a few terminals are seen more medially. The anterior lateralis fibers ascend medial to the posterior lateral line fibers and provide input to the granule cells along their route. In the rostral portion of the eminentia granularis, anterior lateralis 

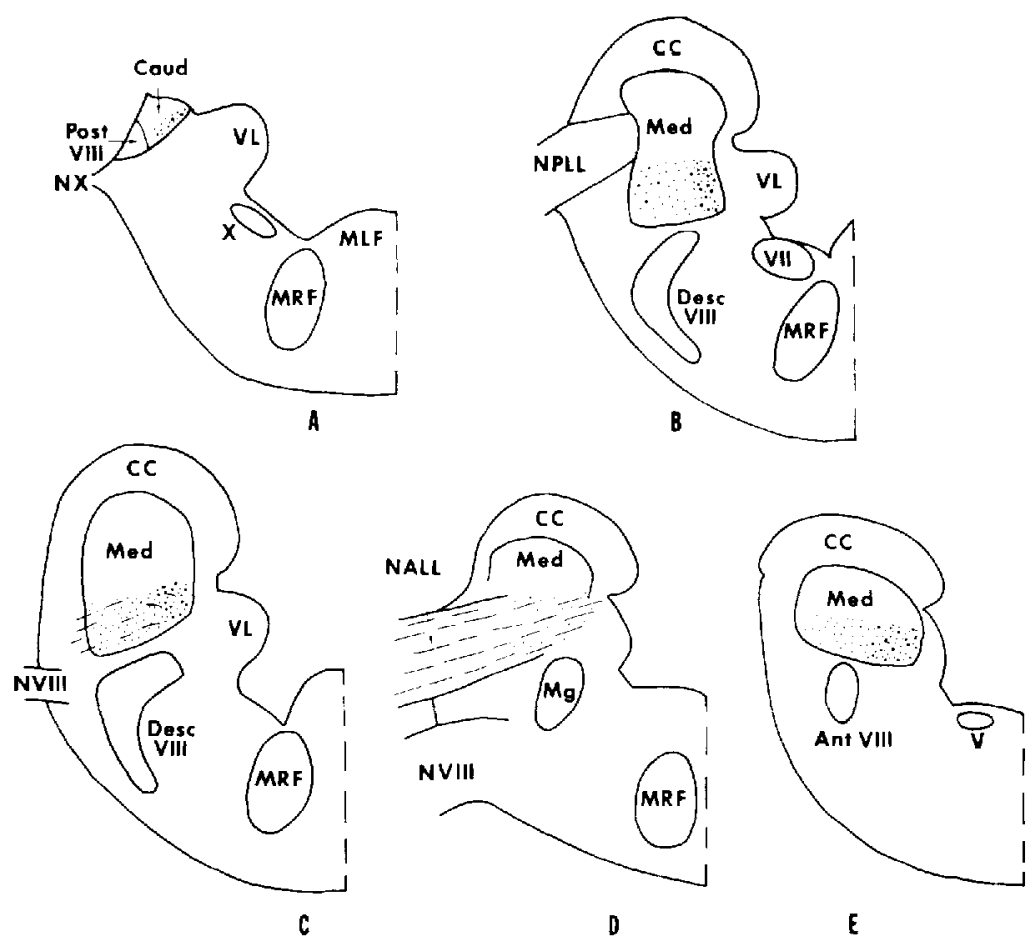

Fig. 4. A-E. Line drawings of transverse sections through the octavolateralis area showing the projections of the anterior lateral line nerve. I evels correspond to those in Figure 3. Dashed lines and heavy dots indicate degenerating axons. Light stippling indicates degenerating terminals.

fibers terminate densely on the granule cells just medial to those which receive posterior lateralis input (Fig. 7B). A very small proportion of the terminals are found more laterally.

\section{Projections of the octavus nerve}

Both rami of the octavus nerve project ipsilaterally to the four nuclei of the octavus column and the connections of the two rami are described together. No contralateral projections were seen.

Some entering octavus fibers course medially and terminate on the somata and dendrites of nucleus magnocellularis (Fig. 6D). However, the bulk of the fibers form ascending and descending bundles on the ventrolateral aspect of the medulla, dorsal to the descending spinal tract of the trigeminal nerve.

Descending fibers supply the descending and posterior octavus nuclei. The descending nucleus is the most extensive termination site of the eighth nerve (Figs. 6B,C, 8C). The majority of fibers distribute to the dorsal portion of this nucleus, while a smaller population of fibers runs ventrally and medially to supply the most ventral division of the descending nucleus. Some of these fibers continue medially and terminate in the ipsilateral medial reticular formation (Fig. 6B,C). Caudal to the descending nucleus, the descending octavus tract moves dorsally, and terminates in the posterior octavus nucleus (Figs. 6A, 9C).

Some ascending fibers terminate within the anterior octavus nucleus (Figs. 6E, 8F), whereas others continue into the eminentia granularis of the cerebellum. Within the eminentia granularis, octavus fibers ascend in a position medial to the anterior lateral line fibers, and terminate on granule cells medial to those receiving lateralis input. Most rostrally, the granule cells of the eminentia lie on the cerebellar surface, and octavus terminals are again seen medial to lateralis terminals (Fig. 7C).

In addition to the projections to the four primary octavus nuclei, the HRP material demonstrates a very small number of scattered eighth 

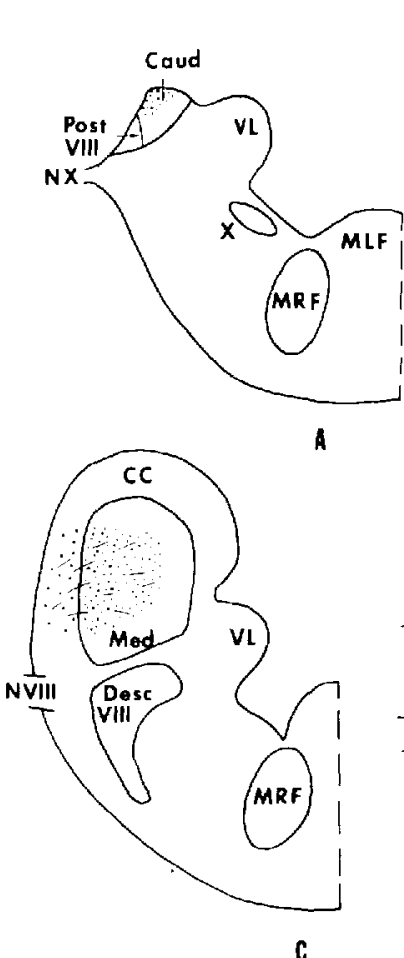

A
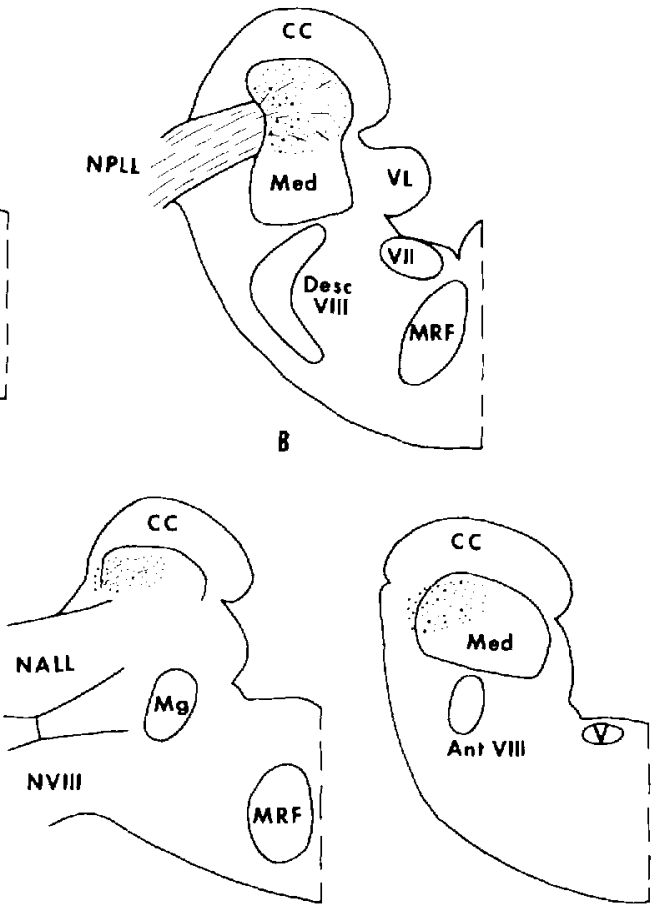

D

E

Fig. 5. A-E. Line drawings of transverse sections through the octavolateralis area showing the projections of the posterior lateral line nerve. Levels correspond to those in Figure 3. Dashed lines and heavy dots indicate degenerating axons. Light stippling indicates degenerating terminals.

nerve fibers in nucleus medialis. A]though most of these fibers appear to be medially coursing contingents of either the ascending or descending octavus tracts, the possibility that some of these fibers terminate within nucleus medialis cannot be ruled out.

\section{Projections of the glossopharyngeal nerve}

The projection of the glossopharyngeal nerve is restricted to portions of the vagal lobe. After entering the medulla, the nerve courses toward the vagal lobe, where it terminates. The glossopharyngeal nerve provides no input to any of the octavolateralis nuclei. The absence of such an input suggests that lateralis fibers are not a component of this nerve proximal to its ganglion.

\section{DISCUSSION}

This study presents a description of the octavolateralis area in Amia which differs from previous descriptions of this species in both the number of constituent nuclei recognized and their afferent connections. In Amia, six medullary nuclei receive first-order lateralis and/or octavus input. Two of these nuclei, nucleus medialis and nucleus caudalis, form the lateralis cell column and receive almost all of the lateralis input to the medulla. Anterior lateralis afferents terminate medially to ventromedially within each of these nuclei, whereas posterior lateralis afferents terminate laterally to dorsolaterally. The octavus cell column is composed of four nuclei which receive input from both rami of the eighth nerve: the anterior, descending, and posterior octavus nuclei and nucleus magnocellularis. There appears to be litthe convergence of lateralis and octavus inputs at the level of these first order nuclei. Such convergence is largely limited to nucleus magnocellularis, which receives a sparse projection from the anterior lateral line nerve as well as a substantial projection from the eighth nerve. Additionally, since the distal dendrites of some of the larger octavolateralis cells of 

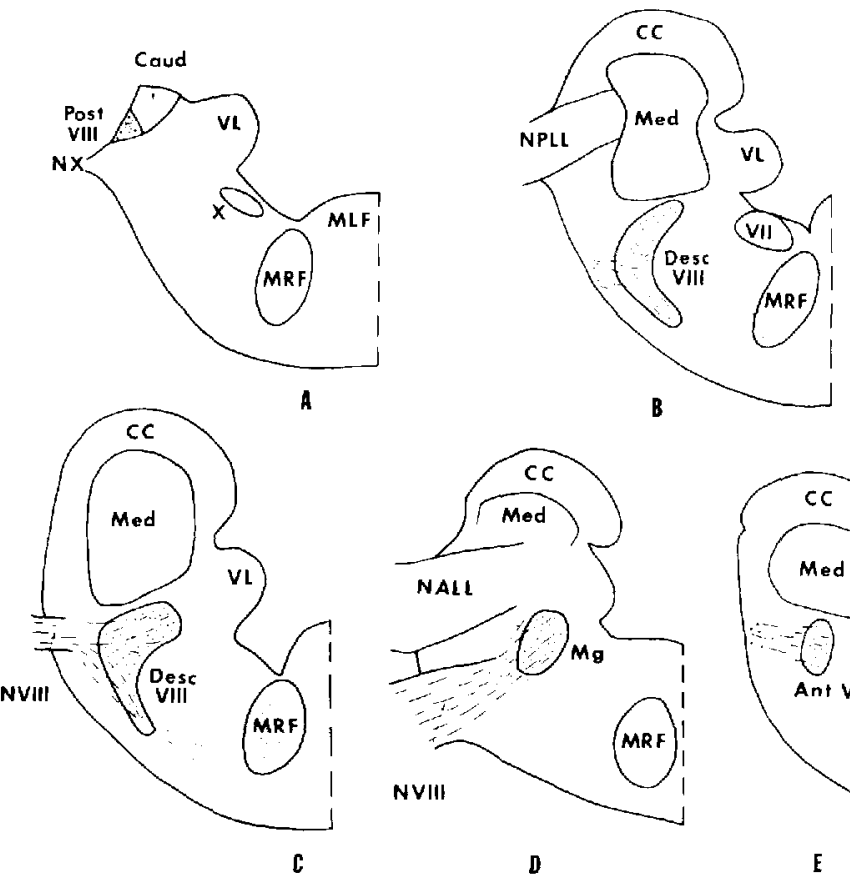

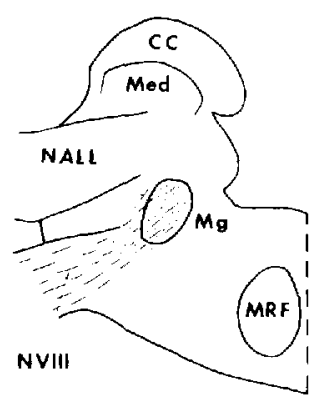

D

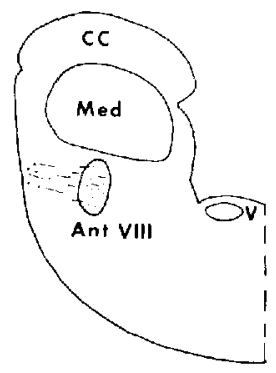

$\mathbf{E}$

Fig. 6. A-E. Line drawings of transverse sections through the octavolateralis area showing the projections of the octavus nerve. Levels correspond to those in Figure 3. Dashed lines and heavy dots indicate degenerating axons. Light stippling indicates degenerating terminals.
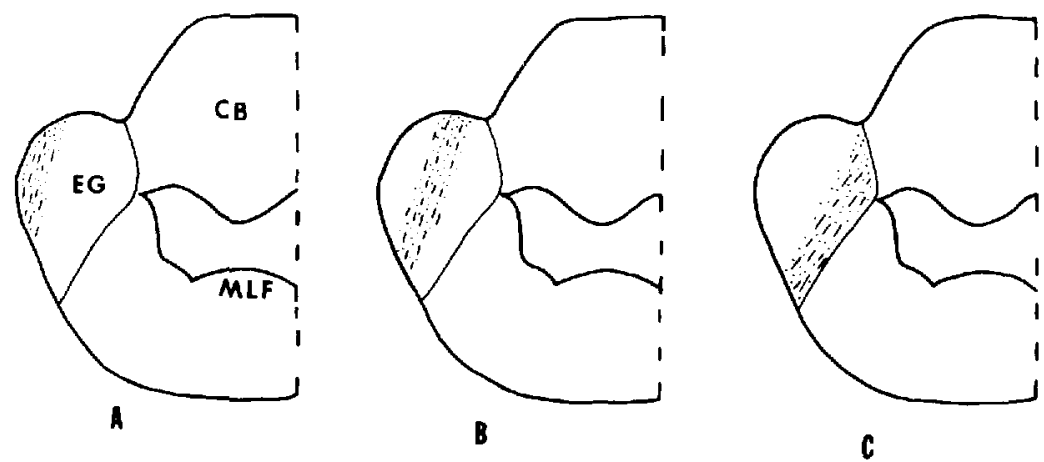

Fig. 7. Transverse sections through the rostral part of the eminentia granularis showing the distribution of degenerating fibers and terminals of $(A)$ the posterior lateral line nerve, $(B)$ the anterior lateral line nerve, and (C) the octavus nerve. The posterior and anterior lateralis tracts occupy lateral and medial positions in the medulla, respectively, and ascend into the eminentia granularis in these same general positions. The octavus tract is located on the lateral surface of the medulla ventral to the posterior lateralis tract. Octavus fibers turn medially as they enter the eminentia granularis, and terminate medial to the lateralis fibers. Dashes indicate degenerating axons, and stippling indicates degenerating terminals. 
each column may extend into the boundaries of the other column, there is therefore the possibility of convergence of input on these cells. By and large, however, the pattern of lateralis and octavus inputs is characterized by their segregation within the lateralis and octavus cell columns, respectively, rather than by extensive overlap. This pattern is also maintained in the terminations of these nerves within the eminentia granularis of the cerebellum, in which octavus fibers tend to terminate medially, and lateralis fibers terminate primarily laterally.

The Mauthner cell may also be a termination site of lateralis and octavus fibers in Amia. Although normal anatomical and physiological studies have reported these inputs in many fish (for a review, see Zottoli, 78), they are not usually visualized using experimental anatomical methods (Maler et al., '73a,b, 74; Bell and Russell, '78; Northcutt, 1979a,b, '80). However, since the lateral dendrite of the Mauthner cell in Amia extends into the octavolateralis area, it is likely that such connections are present. Recently, the saccular branch of the eighth nerve was traced to the Mauthner cell in a teleost fish by means of anterograde HRP labelling (Szabo et al., '78; Bell, '81).

The present findings also indicate that the glossopharyngeal nerve in Amia does not contain lateralis fibers, contrary to the findings of several nonexperimental studies (Allis, 1889; Kingsbury, 1897; Norris, '25). If lateralis components were present, terminations of this nerve would have been found within the lateralis column. However, the connections of the glossopharyngeal nerve were restricted to the vagal lobe-a visceral sensory structure. One explanation of these results is that whereas lateralis fibers may course with the glossopharyngeal nerve peripherally, they separate from it as they approach the medulla and join the anterior or posterior lateralis nerves.

The projections of specific end organs within the otic capsule were not determined in this study. Acoustic functions in bony fish are generally believed to reside in the sacculus and the lagena (Popper and Fay, '73; Popper, in press), whereas the utriculus and semicircular canals subserve gravistatic and acceleration functions, respectively (Lowenstein, '71). Since separate termination sites for the auditory and vestibular modalities have been demonstrated, at least to some extent, in tetrapods as well as in a teleost (Bell, '81), it is possible that the octavus column in Amia may also be organized in this way.

\section{Comparison with nonexperimental studies of Amia}

In contrast to the above results, Pearson (36) and Larsell ('67) delineated fewer nuclei in the octavolateralis, or acousticolateralis, area of Amia and, on the basis of normal fiber analyses, described extensive overlap between the terminations of the eighth and lateral line nerves. These investigators recognized only two octavolateralis nuclei-nucleus medialis, into which both lateralis and octavus fibers were traced, and nucleus ventralis, a recipient of eighth nerve input. Like the nucleus medialis I have described, the nucleus medialis of Pearson and Larsell occupies the dorsal portion of the medulla and underlies the cerebellar crest. However, their nucleus extends farther ventrally and caudally than the nucleus medialis I delineate, and therefore also encompasses some of the octavus nuclei I recognize. This difference in boundaries may partially account for the overlap in inputs which Pearson and Larsell described in this nucleus. Additionally, Pearson subdivided nucleus medialis near its rostral boundary into a small-celled pars dorsalis and a large-celled pars ventralis. I do not consider Pearson's pars dorsalis as part of nucleus medialis and trace no lateralis or octavus fibers to these cells. Pearson's pars ventralis encompasses at least the rostral Purkinje-like cells of nucleus medialis and may also include the ventral portion of this nucleus.

The nucleus ventralis of Pearson is a collection of multipolar cells lying near the medial wall of the medulla; this structure corresponds to the nucleus magnocellularis of the present study. Although the nucleus ventralis of Larsell also contains these large cells, it includes cells both rostral and caudal to them which I recognize as components of other octavus nuclei. While the nucleus ventralis was considered to be a vestibular structure on the basis of its input from the octavus nerve, it is not possible to determine from the present study which of the otic end organs provide afferents to nucleus magnocellularis.

In agreement with the present study, Pearson and Larsell traced both lateralis nerves and the eighth nerve to the eminentia granularis in Amia. Larsell also described projections to the interauricular granular band of the cerebellum, and Pearson traced anterior lateralis fibers to the valvula. 'These latter connections have not been confirmed in the present study. 

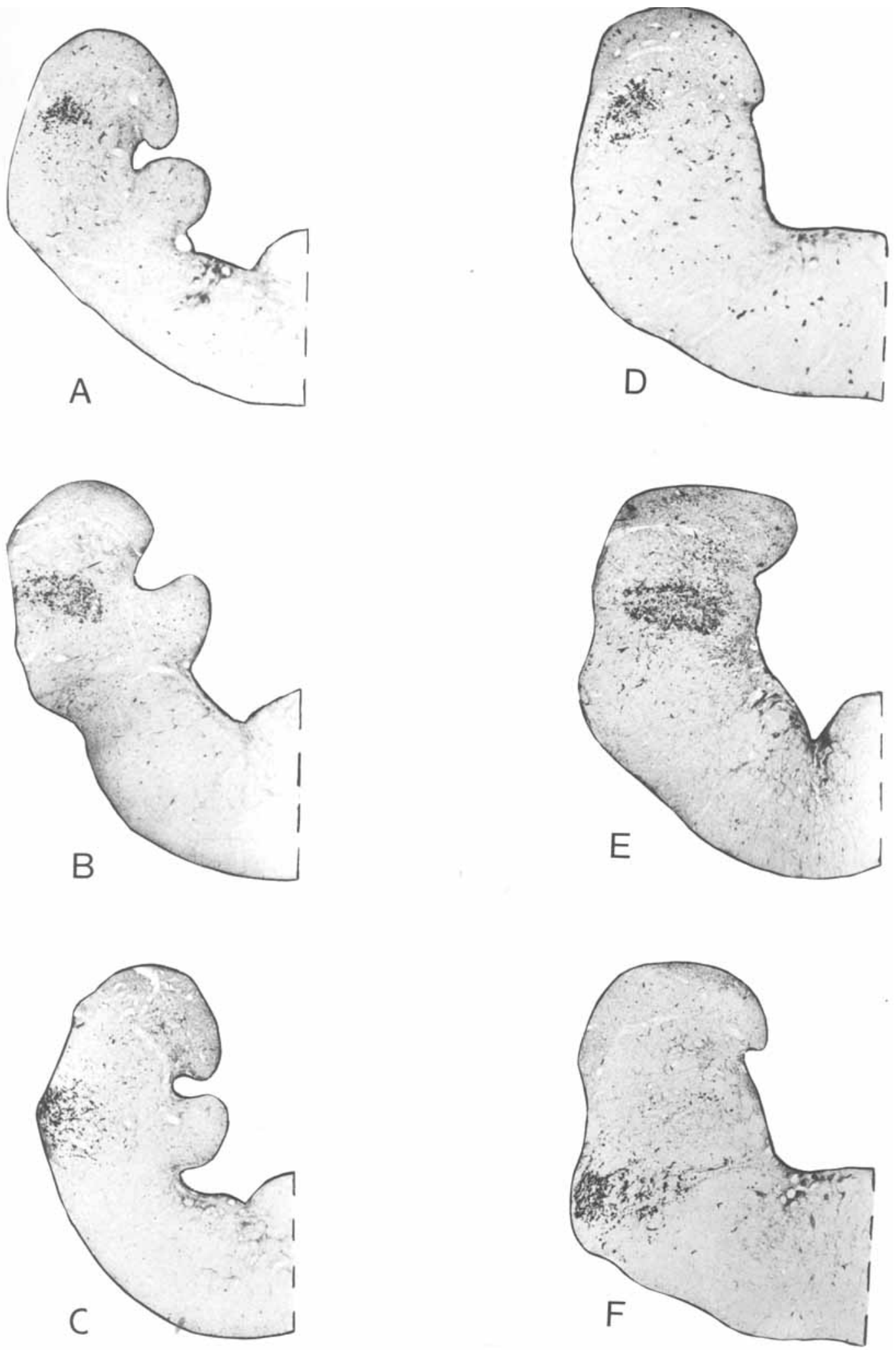
Distribution patterns of the octavus and lateralis nerves within the octavolateralis area in other fish

Most normal anatomical studies of the octavolateralis area concluded that its ventral portion was concerned with vestibular processing while its dorsal portion (nucleus medialis) was characterized by overlap of octavus and lateralis inputs. In contrast, the majority of experimental anatomical studies demonstrate a differential distribution pattern for these nerves similar to that seen in Amia, despite the fact that the species used in these studies span a wide phylogenetic range. These data are outlined in Table 1.

The class Agnatha formed the earliest vertebrate radiation, and is today represented by several species belonging to one order, the Cyclostomata (Romer, '66). In one member of this group, the lamprey Icthyomyzon unicuspis, the lateralis nerves terminate in the dorsal, lateralis area, whereas the termination site of the eighth nerve is confined to a more ventral octavus cell column (Northeutt, '79a, '80). In the Chondricthyes, or cartilaginous fish (sharks, skates, and rays), the lateralis nerves (Boord and Campbell, '77; Koester and Boord, '78; Northcutt, '80) and octavus nerves (Northcutt, '80; Boord and Roberts, '80) also terminate within separate lateralis and octavus cell columns, respectively. As in Amia, nucleus magnocellularis is suggested to be a point of convergence of these nerves (Northcutt, '80). Experimental data on lateralis and eighth nerve projections in the largest vertebrate class, the Osteicthyes, or bony fish, is confined to five species belonging to one subclass, the Actinopterygii, or ray-finned fishes. The Actinopterygii encompasses three major radiations (Romer, '66): the chondrosteans, the holosteans (to which Amia belongs), and the teleosts (the most recent of the radiations). Apart from Amia, the projections of the lateralis and/or octavus nerves are known in only four species: the teleosts Cyprinus carpio (Luiten,
75), Gillicthyes mirabilis (Northcutt, '79b, '80), Gnathonemus petersi (Maler et al., '73a,b; Libouban and Szabo, '77; Szabo et al., '78; Bell and Russell, '78; Szabo and Libouban, '79; Bell, '81), and Apteronotus albifrons (Maler et al., '74).

Anterior lateral line projections in the carp, Cyprinus, are similar to those in Amia in that these fibers terminate within nucleus medialis ipsilaterally (Luiten, '75). In Gillicthyes, a goby, the projections of the octavus nerve are nearly identical to those in Amia (Table 1), supplying the anterior, descending, posterior, and magnocellular octavus nuclei, and the medial reticular formation. Teleosts have an additional octavus nucleus, nucleus tangentialis, and in Gillicthyes first-order fibers terminate in this nucleus (Northcutt, 1979b, '80).

In the mormyrid, Gnathonemus, Maler et al. $(73 \mathbf{a}, b)$ demonstrated largely separate lateralis and octavus cell columns using experimental degeneration methods (Table 1). A similar lateralis column was also defined in the gymnotid Apteronotus (Maler et al., '74). However, other investigators, using anterograde HRP labelling, traced significant projections of the lateral line nerves to the octavus cell column (Bell and Russell, '78; Bell, '81 and of the octavus nerve to the lateralis cell column (Bell, '81 in Gnathonemus. Since some other experimental studies demonstrate or suggest some convergence of first-order lateralis and octavus inputs, albeit sparse (Maler et al., '73a,b; Northcutt, '79a, b; present study), one interpretation of the contrasting results in Gnathonemus is that the extensive convergence of inputs in this species represents a secondary or specialized condition, the significance of which is not yet clear. An additional difference found in this species is the bilateral projections of the octavus and lateralis nerves (Maler et al., '73a,b; Bell and Russell, '78; Bell, '81.

Thus, the general pattern of octavus and lateralis projections demonstrated in most experimental anatomical studies is one in which these inputs are largely processed in separate

Fig. 8. Photomicrographs of transverse sections showing the location of HRP reaction product after injections of the posterior lateral line nerve ( $A, D$ ), anterior lateral line nerve $(B, E)$, and posterior ramus of the eighth nerve $(C, F)$. $A, B$, and $C$ compare the distributions of the three nerves in the caudal portion of the octavolateralis area at a level just caudal to Figure 3B. The posterior lateral line nerve distributes dorsolaterally within nucleus medialis ( $\mathrm{A}$ ), whereas the anterior lateral line nerve (B) terminates ventrally in this structure. The projection of the posterior eighth nerve ramus (C), as well as that of the anterior eighth nerve ramus, is to the descending octavus nucleus. $D$, E, and $F$ ' compare the distributions of the three nerves in the rostral portion of the octavolateralis arca. $\mathrm{D}$ and $\mathrm{F}$ are at a level comparable to that of Figure $3 \mathrm{E}$, while $\mathrm{E}$ is somewhat rostral to this level. The pattern of lateralis input to the rostral portion of nucleus medialis is similar to that seen in its caudal portion, with posterior lateral line fibers terminating dorsolaterally $(D)$ and anterior lateral line fibers terminating ventrally (E). The posterior ramus of the eighth nerve terminates in the anterior octavus nucleus ( $F$ ), as does the anterior ramus of the eighth nerve. 


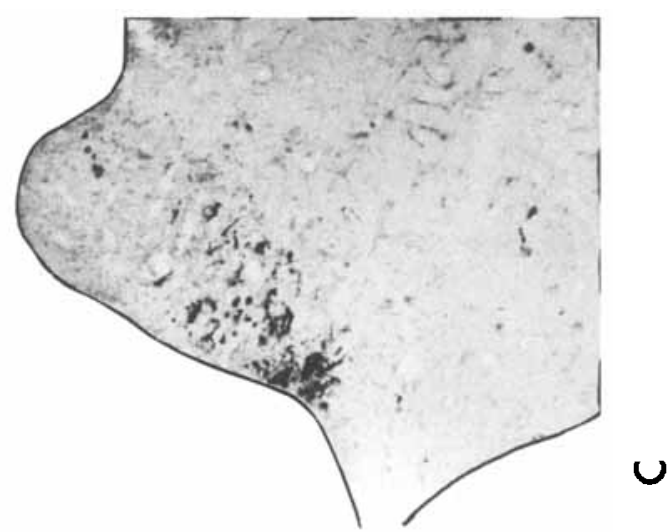

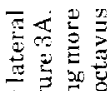

.

\$ 3.3

할

运

政

ह

政

है

过

岁要

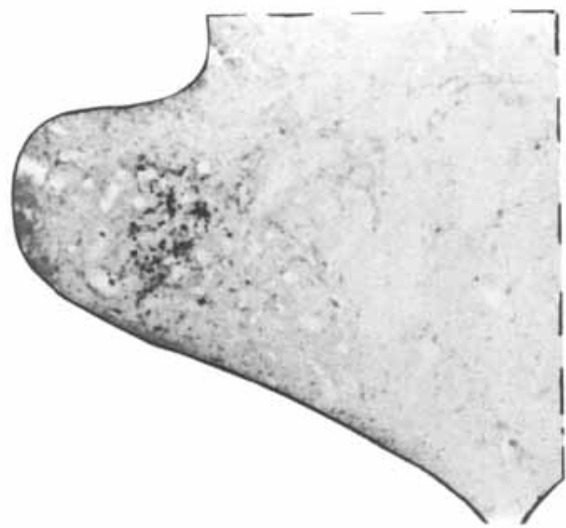

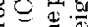

a,

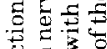

可

$\approx$ aㅇ

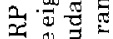

政

동

记

요용

证

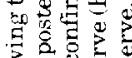

客

कै

现 $\overrightarrow{0}$

保

o

证

क क

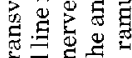

$\pm \pi$,

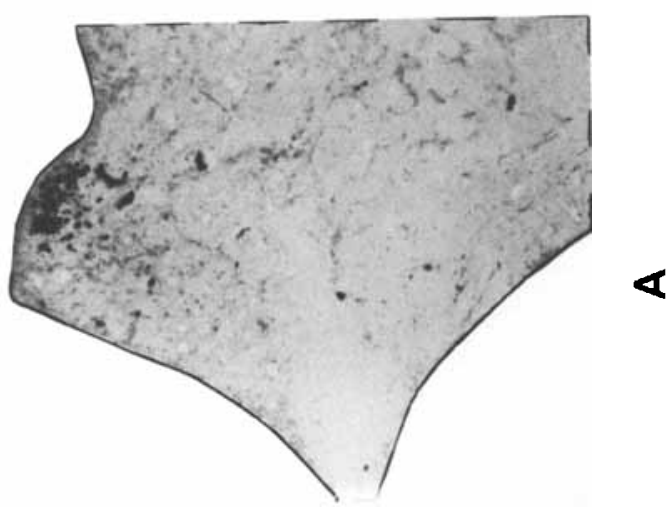

语

$\pi$

政

讨

可 $\approx$

द्वे

要

出

os

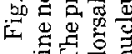




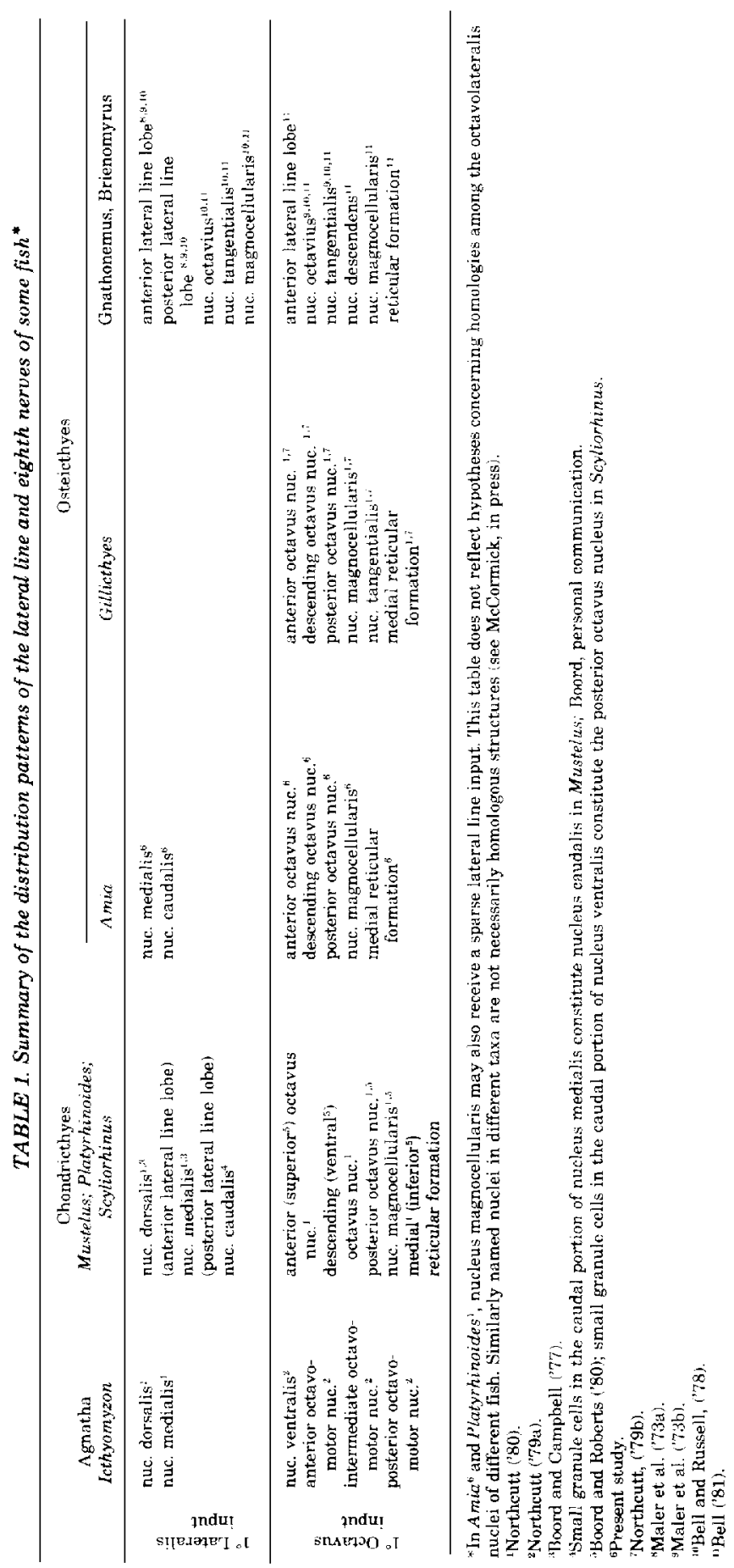


first-order nuclei with little convergence at this level, although the number of species from which these data are derived is small. This pattern holds even though the nuclear constituents of the octavolateralis area may vary among different species (Table 1). While some of the differences in the nomenclature outlined in Table 1 reflect different criteria for subdividing this area, others reflect actual variations in its organization. These variations will be discussed in a later paper.

\section{Distribution of lateralis and octavus fibers within the cerebellum}

In A mia, some fibers of the lateralis and octavus nerves ascend into the ipsilateral eminentia granularis of the cerebellum. Posterior lateralis fibers terminate largely on granule cells in the most lateral portion of this structure, while anterior lateralis fibers generally terminate just medial to these fibers. Some fibers of each octavus nerve ascend to the most medial portion of the eminentia granularis. Almost all experimental investigations in other fish have documented first-order lateralis and octavus input to the ipsilateral cerebellum (Table 1), and in Gnathonemus there are also sparse contralateral projections. In the actinopterygian fishes, these ascending fibers terminate in the eminentia granularis. In Gillicthyes, there is also a more medial input of the octavus nerve to a portion of the granular layer of the cerebellum (Northcutt, '79b, '80). Luiten (75) reports a similar projection of the anterior lateralis nerve in Cyprinus. In addition to octavus and lateralis projections to the eminentia (Maler et al., '73a,b; '74; Libouban and Szabo, '77; Bell and Russell, '78; Bell, '81), the electroreceptive teleosts Gnathonemus and Apteronotus possess a hypertrophied portion of the cerebellum, the lobus caudalis, which receives lateralis fibers and in turn provides input to the medullary electroreceptive region, the posterior lateral line lobe (Maler et al., '74).

The relationships between the cerebellar subdivisions of actinopterygians, chondricthyans, and agnathans are not well understood. However, in chondricthyans, the lateralis and eighth nerves project to lateral and medial portions of the vestibulo-cerebellum, respectively (Boord and Campbell, '77; Koester and Boord, '78; Northcutt, '80; Boord and Roberts, '80). Finally, in the agnathan Icthyomyzon, the eighth nerve terminates ipsilaterally in the molecular and cellular layers of the cerebellum (Northcutt, '79a, '80); there have been no recent attempts, based on experimental data, to compare the agnathan cerebellum with that of bony fish (however, see Larsell, '67; Nieuwenhuys, '67).

\section{Functional considerations}

The lateral line and otic end organs are traditionally considered as components of a single (acousticolateralis) system. The notion that these end organs are phylogenetically related and functionally similar (Beard, 1884; Ayers, 1892; van Bergeijk, '67) received support from early studies that described common medullary termination sites for the lateralis and eighth nerves. The lateralis system, for example, has traditionally been classified as an acoustic receptor accessory to those of the otic capsule, or as the entire auditory apparatus in certain fish. However, the contribution of the lateralis system to auditory sensitivity in fish is largely unknown (Offut, '74); in fact, the specific functions of this sensory system have not yet been determined. Various investigators have suggested that the lateralis system is receptive to water displacements resulting from sources other than underwater sound (Dijkgraaf, '63, '67; Schwartz, '67; Cahn, '72; Pitcher et al., '76), and it is therefore possible that the lateralis and acoustic systems constitute two separate sensory systems. Recent anatomical data lend support to this speculation, in that the differing primary inputs of the lateralis and octavus end organs suggest that lateralis and auditory stimuli are of different biological or behavioral relevance. Future studies which specifically seek to discriminate between the functions of the lateralis and auditory systems can be expected to provide a more conclusive interpretation of these anatomical data.

\section{ACKNOWLEDGMENTS}

I am grateful to Dr. R.G. Northcutt for his guidance and support throughout my graduate training and in the preparation of this manuscript. I am also appreciative of the guidance of Dr. M.R. Braford, Jr. throughout the course of this study, and to Dr. A. N. Popper for support during its later phases. I would also like to thank Dr. R. Nieuwenhuys for generously providing me with the photographic negatives used to construct Figure 3, and Dr. A.B. Butler for her comments on the manuscript. This report is partially based on the author's doctoral dissertation at The University of Michigan. Supported in part by NIH grant 2 ROI NS 11006 to Dr. R.G. Northcutt, NSF grant BNS 782241 to Dr. A. N. Popper, and a Rachkam Dissertation grant from The University of Michigan to the author. 


\section{LITERATURE CITED}

Allis, F.P. Jr. (1889) The anatomy and development of the lateral line system in Amia calva. J. Morphol. 2:463 568.

Ayers, H. (1892) Vertebrate cephalogenesis. II. A contribution to the morphology of the vertehrate ear, with a reconsideration of its functions. J. Morphol. 6:1 -360 .

Bauknight, R.S., D. Strelioff, and V. Honrubia (1976) Effective stimulus for the Xenopus laevis lateral-line haircell system. Laryngoscope 86:1836-1844.

Beard, J. (1884) On the segmental sense organs of the lateral line, and on the morphology of the vertebrate auditory organ. Zool. Anz. 7:123-126.

Bell, C. (1981) Central distribution of octavolateral afferents and efferents in a teleost (Mormyridae). J. Comp. Neurol. 195:391-414.

Bell, C.C., and C.J. Russell (1978) Termination of electroreceptor and mechanical lateral line afferents in the mormyrid acousticolateral area. J. Comp. Neurol. 182:367-382.

Boord, R.L. and C.B.G. Campbell (1977) Structural and functional organization of the lateral line system of sharks. Am. Zool. 17:431-441.

Boord, R.L. and L.M. Eiswerth (1972) The central terminal fields of posterior lateral line and eighth nerves of Xenopus. Am. Zool. 12:727.

Boord, R.L., and B.L. Roberts (1980) Medullary and cerebellar projections of the statoacoustic nerve of the dogfish, Scyliorhinus canicula. J. Comp. Neurol. 19.3:57-68.

Cahn, P. (1972) Sensory factors in the side-to-side spacing and positional orientation of the tuna, Euthynnus affinis, during schooling. Fish. Bull. 74:471-502.

Campbell, C.B.G., and R.L. Boord (1974) Central auditory pathways of nonmammalian vertebrates. In: Handbook of Sensory Physiology. W.D. Keidel and W.D. Neff, eds. Springer-Verlag, New York, vol. V/1, pp. 337-362.

Dijkgraaf, S. (1963) The functioning and significance of the lateral line endorgans. Biol. Rev. 38:51-105.

Dijkgraaf, S. (1967) Biological significance of the lateral line organs. In: Lateral Line Detectors. P.H. Cahn, ed. Indiana University Press, Bloomington. pp. 83-95.

Harris, G.G. and W.A. van Bergeijk (1962) Evidence that the lateral line organ responds to near-field displacements of sound sources in water. .J. Acoust. Soc. Am. 34:1834 1841 .

Kingsbury, B.F. (1897) The structure and morphology of the oblongata in fishes. J. Comp. Neurol. 7:1-36.

Koester, D.M., and R.L. Boord (1978) The central projections of first order anterior lateral line neurons of the clearnose skate, Raja eglanteria. Am. Zool. 18:587.

Kroese, A.B.A., J.M. Van der Zalm, and J. Van den Bercken (1978) Frequency response of the lateral-line organ of Xenopus laevis. Pflug. Arch. 375:167-175.

Larsell, O. (1967) The Comparative Anatomy and Histology of the Cerebellum from Myxinoids through Birds. J. Jansen, ed. Univ. Minnesota Press, Minneapolis.

Libouban, S., and T. Szabo (1977) An integration centre of the mormyrid fish brain: The auricula cerebelli. An HRP study. Neurusci. Letters 6:115-119.

Lowenstein, O. (1971) The labyrinth. In: Fish Physiology. W.S. Hoar and D.J. Randall, eds. Academic Press, New York, vol. V. pp. 207-240

Luiten, P.G.M. (1975) The central projections of the trigeminal, facial, and anterior lateral line nerves in the carp (Cyprinus carpio L.) J. Comp. Neurol. 160:399-418.

Maler, L., H.J. Karten, and M.V.L. Bennett (1978ai The central connections of the posterior lateral line nerve of Gnathonemus petersi. J Comp. Neurol. 151:57-66

Maler, L., H.J. Karten, and M.V.L. Bennett (1973b) The central connections of the anterior lateral line nerve of Gnathonemus petersi. J. Comp. Neurol. 151:67-84

Maler, L,, T. Finger, and H.J. Karten (1974) Differential projections of ordinary lateral line receptors and electroreceptors in the gymnotid fish, Apteronotus (Sternarchus) alhifrons. J. Comp. Neurol. 158:363-382.

McCormick, C.A. (1978) Central Projections of the Lateralis and Eighth Nerves in the Bowfin, Amia calva. Doctoral Dissertation, The University of Michigan.

McCormick, C.A. Oryanization and evolution of the octavolateralis area of fishes: In: Fish Neurobiology. R.G. North cutt and R.E. Davis, eds. The University of Michigan Press, Ann Arbor, vol. 1. (in press).

Mesulam, M.M. (1978) Tetramethyl benzidine for horseradish peroxidase neurohistochemistry: A non-carcinogenic blue reaction-product with superior sensitivity for visualizing neural afferents and efferents. J. Histochem. Cytochem. 26:106-117.

Nieuwenhuys, R. (1967) Comparative anatomy of the cerebellum. In: Progress in Brain Research. C.A. Fox and R.S. Snider, eds. Elsevier, New York, Vol. 25, pp. 1-93.

Norris, H.W. (1925) Observations upon the peripheral distribution of the cranial nerves of certain ganoid fishes (Amia, Lepidosteus, Polyodon, Scaphirhynchus and Acipenser). J. Comp. Neurol. 39:345-432.

Northcutt, R.G. (1979a) Central projections of the eighth cranial nerve in lampreys. Br. Res. 167:163-167.

Northcutt, R.G. (1980) Central auditory pathways in anamniotic vertebrates. In: Comparative Studies of Hear. ing in Vertebrates. A.N. Popper and R.R. Fay, eds. Springer-Verlag, New York pp. 79-118.

Northcutt, R. G. (1979b) Primary projections of VIII nerve afferents in a teleost, Gillicthyes mirabilis. Anat. Rec. 193:638.

Offut, G.C. (1974) Structures for the detection of acoustic stimuli in the Atlantic codfish, Gadus morhua. .f . Acoust. Soc. Am. 56:665-671

Pearson, A.A. (1936) The acustico-lateral centers and the cerebellum, with fiber connections, of fishes. J. Comp. Neurol. 65:201-294.

Pitcher, T.J., B.L. Partridge, and C.S. Wardle (1976) A blind fish can school. Science 194:963-965.

Popper, A.N. Organization of the inner ear and auditory processing. In: Fish Neurobiology. R.G. Northcutt and R.E. Davis, eds. Unjv. of Michigan Press, Ann Arbor, vol. 1, (in press).

Popper, A.N., and R.R. Fay (1973) Sound detection and processing by teleost fishes: A critical review. J. Acoust. Soc. Am. 53:1515-1529

Rasmussen, G.L. (1961) A method of staining the statoacoustic nerve in bulk with Sudan Black B. Anat. Rec. 139:465470 .

Retzius, B. (1881) Das Gehororgan der Wirbelthiere. Samson and Wallin, Stockholm, vol. 1.

Romer, A.S. (1966) Vertebrate Paleontology. 3rd edition. Lniversity of Chicago Press, Chicago.

Schwartz, E. (1967) Analysis of surface-wave perception in some teleosts. In: Lateral Line Detectors. P.H. Cahn, ed. Indiama University Press, Bloomington, pp. 123-134.

Strelioff D., and V. Honrubia (1978) Neural transduction in Xenopus laevis lateral line system. J. Neurophysiol. 41: 432444.

Szabo, T., M. Ravaille, and S. Libouban (1978) Club endings of primary afferent fihers identified by anterograde horseradish peroxidase labelling. An EM study. Neurosci. Letters $9: 7-15$

Suabo, T., and S. I.ibouban (1979) On the course and origin of cranial nerves in the teleost fish Gnathonemus determined by ortho- and retrograde horseradish peroxidase axonal transport. Neurosci. Letters $11: 265-270$.

van Bergeijk, W.A. (1967) The evolution of vertebrate hearing. In: Contributions to Sensory Physiology. W.D. Neff, ed. Academic Press, New York, vol. 2, pp. 1-49.

van der Horst, C.J. (1925) The cerebellum of fishes. I. General morphology of the cerebellum. Proc. $R$. Acad. Amster. 28:735-746.

Wiitanen, J.T. (1969) Selective impregnation of degenerating axons and axon terminals in the central nervous system of the monkey (Macaca mulatta). Br. Res. 14:546-548.

Zottoli, S. (1978) Comparative morphology of the Mauthner cell in fish and amphibians. In: The Neurobiology of the Mauthner Cell. D.S. Faber and H. Korn, eds. Raven Press, New York, pp. 13-45. 